\title{
PHYSICAL MODELING OF SUPERSONIC FLOW OVER BODIES WITH PLANE AND AXISYMMETRIC SHAPE
}

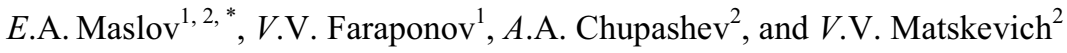 \\ ${ }^{1}$ National Research Tomsk State University, 364050 Tomsk, Russia \\ ${ }^{2}$ National Research Tomsk Polytechnic University, 364050 Tomsk, Russia
}

\section{Introduction}

One of the major stages in methods development of internal ballistic performance calculation for propulsion (thrust, density impulse, the fuel burning rate, pressure-chamber, etc.) is a simulation of the structure and definition of the gas encircling flow parameters. During the operation of the engine by supersonic flowing, the verification of the developed mathematical models on the basis of a comparison with experimental data is required due to the complexity of the intra-chamber processes and changes in performance duct tract geometry. Field tests of the engines are conducted to obtain the necessary data on the main parameters of the process, but it is due to the high material costs. A comparative analysis of numerical and experimental data obtained by laboratory model tests is the most efficient way to obtain objective experimental data.

This paper presents the results of an experimental study of one of the main parameters of supersonic air stream over bodies with plane and axisymmetric shape in the range of Mach number $\mathrm{M}=(2 \div 5)$.

\section{Description of the experimental setup}

The experiments were performed on a model aerodynamic unit (MAU) [1] in the open airwith ambient atmospheric pressure measuring of the equalization chamber pressure and of the installation air flow duct pressure and visualizing of the flow structure.

The experiments were conducted on two types of models: cone-shaped andwedge shaped. The semi-vertex angle was $15^{\circ}$. Models were mounted on a standwith the help of a holder, allowing the pitch angle to vary. Fig. 1 shows photographs of models. Fig. 2 shows a photograph of the wedge-shaped model mounted on the MAU.

Corresponding author: maslov_eugene@mail.ru 


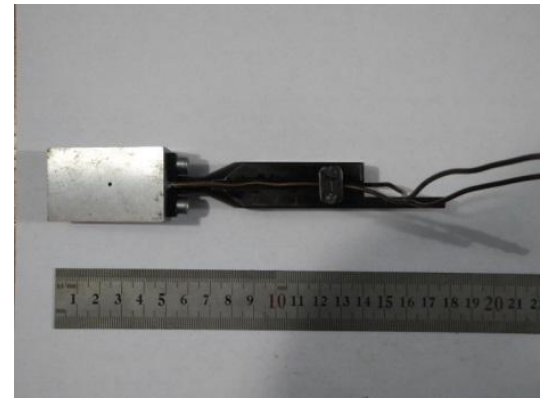

a)

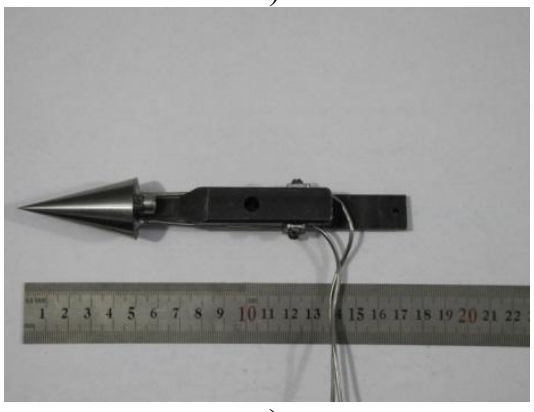

c)

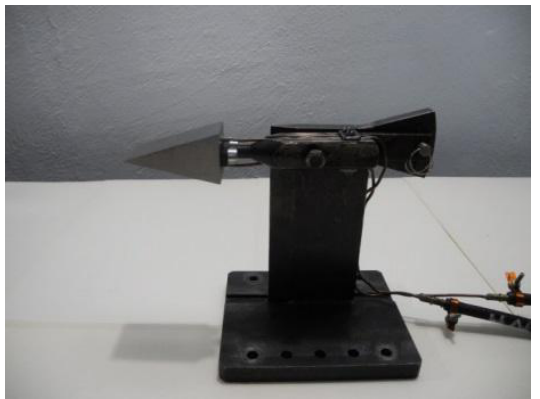

b)

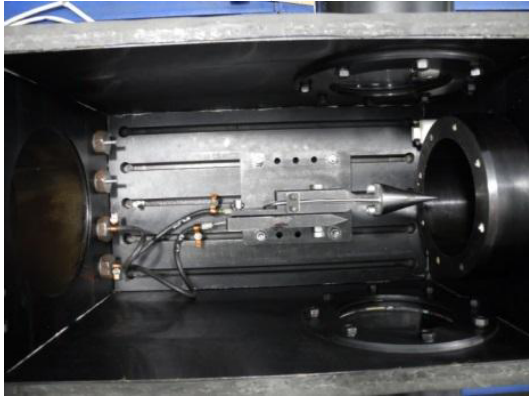

d)

Fig. 1. Models: a) - general view of the wedge model; b) - wedge on a holder; c) - general view of the cone model; d) -working part MAU with the established cone model.

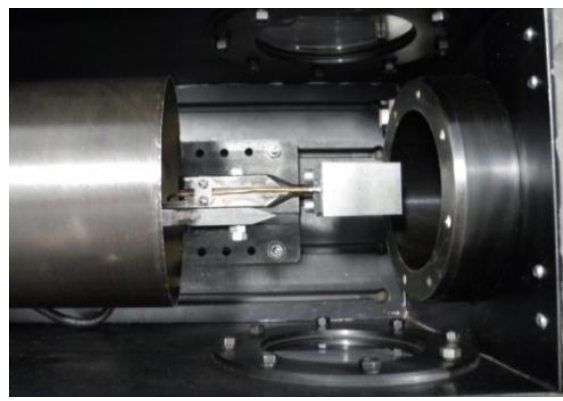

Fig. 2. The cone-shaped model installed on the MAU(top view).

The pressure in the prechamber and in the MAU air flow duct was measured in the course of the experiments. The pressure of gas cylinders with compressed air was controlled as well. The prechamber pressure was measured by a sensor type "DM 5007A DIU2". The pressure was measured near the working chamber rear wall by two pressure sensor units, each of which contains five pressure sensors "TDM2-A" for MAU control mode during the test. All pressure sensors are connected to the digital recording equipment. The signals are received from the pressure sensors on ADC. Signals were recorded by the computer and saved in a file. The program developed by the authors was used for data processing. This program allows counting the received voltage values into values of pressure (in atmospheres). Combined pressure sensors developed by Central Aerohydrodynamic Institute, which make it possible to measure both pressures simultaneously (Pitot-Prandtltube) were used for measuring the total and static pressure in the experiments of supersonic air flow in the MAU working chamber. The measured values of the pressure allowed us to calculatethe air flow Mach number in the MAU working chamber. 
Static pressure was measured by means of selective pipe connecting a hole on the model surface with pressure sensor. The holes were made on the surface of the model (fig. 1, a) for the gas selection. The holes on the surface were made in specific fixed positions in the vertical plane. In the experiments, pressure selection in two opposite points is required for monitoring the accuracy of determining the tangage angle.

\section{Results}

Fig. 3 shows the results of the series of experiments for the plane (wedge-shaped) and the axisymmetric (cone-shaped) models of air flow in the range of Mach numbers $M=(2 \div 5)$ at an angle of tangage $0^{\circ}$.

Analysis of the results showed a difference in pressure values on the surface of the wedge and the cone in this flow velocity range. This effect is explained by the fact that the flow past the cone has a spatial nature. This contributes to a smoother change in the gas flow direction as compared to flow past the wedge [2]. It should be mentioned that the pressure values difference for flow past the plane and axisymmetric models decreases with increasing circumfluent flow rate.

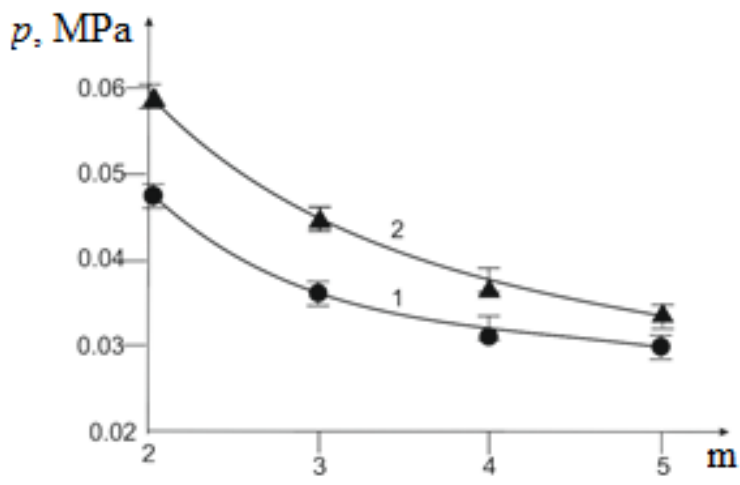

Fig. 3. The pressure at a fixed point on the side surface models: 1 - the cone; 2 - the wedge.

Based on the experimental results of the study it can be concluded that it is necessary to take into account spatial nature of the flow while conducting the mathematical modeling of dynamic processes in propulsion systems in the range of $\mathrm{M}=(2 \div 5)$.

\section{Acknowledgments}

The article was written as part of a research project No. 8.2.46.2015, carried out with the support of the Program "Tomsk State University Research Foundation them. D.I. Mendeleev" in 2015.

\section{References}

1. V. Zvegintsev Gas-dynamic installation short-acting. Part 1: Settings for scientific research (Parallel, Novosibirsk, 2014)

2. N. Krasnov, V. Mishka, A. Danilov, The aerodynamics of questions and problems (Higher. School, Moscow, 1985) 